\title{
Pressure-Temperature Phase Relations in Complex Hydrides
}

\author{
B. Sundqvist \\ Department of Physics, Umeå University, SE-90187 Umeå, Sweden \\ bertil.sundqvist@physics.umu.se
}

Keywords: High pressure, phase diagram, structure, hydrides, $\mathrm{LiAlH}_{4}, \mathrm{Li}_{3} \mathrm{AlH} \mathrm{H}_{6}, \mathrm{NaAlH}_{4}, \mathrm{Na}_{3} \mathrm{AlH}$, $\mathrm{LiBH}_{4}, \mathrm{NaBH}_{4}, \mathrm{KBH}_{4}, \mathrm{Mg}$ hydrides, X-ray diffraction, Raman spectroscopy, thermal conductivity.

\begin{abstract}
Interest in hydrogen as a future energy carrier in mobile applications has led to a strong increase in research on the structural properties of complex alkali metal and alkaline earth hydrides, with the aim to find structural phases with higher hydrogen densities. This contribution reviews recent work on the structural properties and phase diagrams of these complex hydrides under elevated pressures, an area where rapid progress has been made over the last few years. The materials discussed in greatest detail are $\mathrm{LiAlH}_{4}, \mathrm{NaAlH}_{4}, \mathrm{Li}_{3} \mathrm{AlH}_{6}, \mathrm{Na}_{3} \mathrm{AlH}_{6}, \mathrm{LiBH}_{4}, \mathrm{NaBH}_{4}$, and $\mathrm{KBH}_{4}$. All of these have been studied under high pressure by various methods such as X-ray or neutron scattering, Raman spectroscopy, differential thermal analysis or thermal conductivity measurements in order to find information on their structural phase diagrams. Based mainly on experimental studies, preliminary or partial phase diagrams are also given for six of these materials. In addition to this information, data are provided also on experimental results for a number of other complex hydrides, and theoretical predictions of new phases and structures under high pressures are reviewed for several materials not yet studied experimentally under high pressure.
\end{abstract}

\section{Introduction}

Over the last few years it has become increasingly clear that oil products must be replaced as energy carriers in mobile applications in a not very distant future. Among several possible candidates, hydrogen has emerged as an environmentally friendly alternative, especially when used in efficient fuel cells where the end product of the reaction theoretically is only water. However, although hydrogen has many desirable properties it also has several practical drawbacks, and one of the most serious of these is that hydrogen has a very low density. To store pure hydrogen in quantities sufficiently large to give an acceptable driving range requires much larger volumes than required for storage of petrol in present-day vehicles, irrespectively of whether it is stored in the form of compressed gas, liquid, or even a solid. However, as discussed by Schlapbach and Züttel [1], significantly higher mass densities of hydrogen can be obtained if it is stored in the form of solid hydrides. Although very high hydrogen densities can be obtained in rare earth or transition metal compounds such as $\mathrm{LaNi}_{5} \mathrm{H}_{6}$ and $\mathrm{Mg}_{2} \mathrm{NiH}_{4}$, the weight fraction of hydrogen is low in these heavy materials. Light complex hydrides, such as alkali metal and alkaline earth aluminium hydrides and borohydrides, have therefore recently emerged as another interesting class of materials. These contain mass fractions of hydrogen of up to 18 and 20.7 weight percent (in $\mathrm{LiBH}_{4}$ and $\mathrm{Be}\left(\mathrm{BH}_{4}\right)_{2}$, respectively), and in many of these compounds the atomic mass density of hydrogen is higher than in pure solid $\mathrm{H}_{2}$.

An ideal storage material should be able to store and release hydrogen in large quantities by a simple, stable, and reversible mechanism. The discovery that sodium aluminium hydride (sodium alanate), $\mathrm{NaAlH}_{4}$, could reversibly store and release hydrogen in a simple cycle controlled by temperature and hydrogen pressure [2] therefore sparked a very strong interest in this family of materials. Also, an ideal material should contain as large as possible weight and volume fractions of hydrogen. For a given composition the density should thus be maximized, and another interesting branch of hydrogen storage studies appeared after a theoretical calculation predicted that $\mathrm{LiAlH}_{4}$ should have a structural phase transition at high pressure near $2.5 \mathrm{GPa}$, involving an increase in 
density by $17 \%$ [3]. It was immediately realized that if such a dense structure could be stabilized at atmospheric pressure by the addition of impurities, in mixed materials, or by the intrinsic tendency toward metastability in these materials, the volumetric storage capacity would also increase by the same fraction. However, little was known about possible dense structures appearing under high pressure, since very few accurate data about the structural pressure-temperature phase diagrams were available for complex hydrides, and a serious evaluation of this possibility was difficult. Several groups worldwide therefore started systematic investigations of the high-pressure structural phase diagrams of these materials, both experimental and theoretical. This work has already resulted in a significant increase in our knowledge in this field, and for some complex hydrides the phase diagrams have now been mapped over wide ranges in temperature and pressure.

In this review, a brief overview of the results obtained so far on the high-pressure phase relations and phase diagrams of complex hydrides will be given. The paper will concentrate as far as possible on experimental results since theoretical predictions of the structural phase evolution with temperature and pressure by calculations of the total energies of different structures have not always been very successful, due both to the appearance of new structures not foreseen in the calculations and because of the very small differences in energy between different structures. Because most recent work has concentrated on the alkali metal borohydrides and alanates these families will be discussed in detail in this paper, but other complex hydrides will also be very briefly discussed in the last section.

\section{Alkali Metal Aluminium Hydrides (Alanates)}

Among the alkali metal aluminium hydrides (alanates), the vast majority of the studies carried out have been devoted to $\mathrm{LiAlH}_{4}$ and $\mathrm{NaAlH}_{4}$, since it was discovered a few years ago that sodium alanate, $\mathrm{NaAlH}_{4}$, could reversibly store and release hydrogen in the presence of a catalyst, usually Ti [2]. Recent experimental results indicate a possibility that the lithium compound might also be used for reversible hydrogen storage [4,5]. Theoretically, $\mathrm{LiAlH}_{4}$ and $\mathrm{NaAlH}_{4}$ may reversibly release 7.9 and $5.6 \mathrm{wt} . \%$ of hydrogen, respectively, in the presence of suitable catalysts $[2,4]$. Taking $\mathrm{NaAlH}_{4}$ as an example, the process involves two reversible reactions,

$$
6 \mathrm{NaAlH}_{4} \leftrightarrow 2 \mathrm{Na}_{3} \mathrm{AlH}_{6}+4 \mathrm{Al}+6 \mathrm{H}_{2} \leftrightarrow 6 \mathrm{NaH}+6 \mathrm{Al}+9 \mathrm{H}_{2}
$$

which in the presence of a catalyst may occur with a reasonable dynamics in temperature and pressure ranges below about $200^{\circ} \mathrm{C}$ and 150 bar hydrogen pressure [2,6]. $\mathrm{LiAlH}_{4}$ has been reported to react in a similar way [4], although only partial rehydrogenation was achieved by the reverse reaction; recent calculations [7,8] indicate that the dissociation of $\mathrm{LiAlH}_{4}$ into $\mathrm{Li}_{3} \mathrm{AlH}_{6}, \mathrm{Al}$ and $\mathrm{H}_{2}$ should be irreversible. (However, a different, relatively simple rehydrogenation process has recently been developed also for this compound [5].) Because either or both of the two reactions in Eq. 1 can be used as the basis for a hydrogen storage system, the phase diagrams of both $\mathrm{MAlH}_{4}$ and $\mathrm{M}_{3} \mathrm{AlH}_{6}$ (with $\mathrm{M}$ an alkali metal) are of scientific and technological interest. Because of their relatively lower hydrogen contents, the heavy alkali metal compounds have so far been little studied.

At room temperature and atmospheric pressure the complex hydrides form relatively simple structures based on alkali metal ions and hydride complexes such as $\mathrm{AlH}_{4}{ }^{-}$and $\mathrm{BH}_{4}{ }^{-}$. The latter are basically tetrahedral but are sometimes slightly distorted.

Lithium Aluminium Hydrides. The recent theoretical prediction of a phase transformation involving a large density increase by $17 \%$ in $\mathrm{LiAlH}_{4}$ at rather accessible pressures near $2.5 \mathrm{GPa}$ [3] caused a strong increase in the interest in the high pressure properties of the complex hydrides. $\mathrm{LiAlH}_{4}$ is actually one of the few complex hydrides whose structural phase diagrams had been investigated rather well under high pressure by both in situ and ex situ methods, but none of these studies had revealed any indications of a phase transformation at such low pressures. However, ex situ methods rely on the metastability of high-pressure phases and cannot detect reversible phase 
changes, and the only early studies carried out in situ were rather crude resistance measurements under either static $[9,10]$ or dynamic [11] pressures.

In an early ex situ structural investigation, Bulychev et al. [12] treated high purity $\mathrm{LiAlH}_{4}$ at temperatures between 25 and $900^{\circ} \mathrm{C}$ at pressures of 4-7 GPa, then quenched the material to room temperature and released pressure. The samples were investigated by X-ray diffraction (XRD), differential thermal analysis (DTA) and IR spectroscopy to find any new phases metastable under ambient conditions. Samples treated at room temperature and $7 \mathrm{GPa}$ contained only the original $\alpha$ phase (monoclinic structure with symmetry $P 2_{1} / c$ ), but two metastable phases were reported for samples heated at high pressure. Treatment at temperatures between 100 and $400^{\circ} \mathrm{C}$ resulted in the formation of a tetragonal $\beta$ phase; while between 400 and $600^{\circ} \mathrm{C}$ an orthorhombic $\gamma$ phase was reported. The latter phase also appeared after heating to $400^{\circ} \mathrm{C}$ at lower pressures, while heating to $900^{\circ} \mathrm{C}$ resulted in decomposition and release of hydrogen. Both new phases were reported to transform back into the initial $\alpha$ phase on heating to above $105^{\circ} \mathrm{C}$ at atmospheric pressure, and dissolving the pressure treated samples in ether also resulted in recovery of the $\alpha$ phase after evaporation of the solvent. Later, Bastide et al. [13] treated both $\mathrm{LiAlH}_{4}$ and $\mathrm{LiAlD}_{4}$ (with identical results) at $2.5 \mathrm{GPa}$ and $250^{\circ} \mathrm{C}$ for two hours and studied the quenched materials under ambient conditions by XRD and Raman scattering. They tentatively identified the new material as the $\gamma$ phase, commented on the large density increase by about $30 \%$ relative to the starting $\alpha$ phase, and also re-indexed the lattice as monoclinic rather than orthorhombic. Again, thermal studies indicated that on heating to above $100^{\circ} \mathrm{C}$ the new phase reverted to the original $\alpha$ phase with a strong endothermal effect. IR and Raman data from the two investigations indicate a change in the coordination number for the $\mathrm{Al}$ atoms from four to six.

The results of these two studies were somewhat contradictory and questions remained whether $\mathrm{LiAlH}_{4}$ dissociates into $\mathrm{Li}_{3} \mathrm{AlH}_{6}$ as indicated by Eq. 1 also under high pressure. A more recent detailed investigation by Konovalov et al. [14] up to $4.5 \mathrm{GPa}$ and $1273 \mathrm{~K}$ by both in situ DTA measurements and by ex situ structural studies on specimens recovered from high pressure resolved these questions by showing that $\mathrm{LiAlH}_{4}$ was indeed converted into $\mathrm{Li}_{3} \mathrm{AlH}_{6}$ also under pressure, in agreement with Eq. 1. The previously reported $\gamma$ phase was identified as a mixture of reaction products, including $\mathrm{Li}_{3} \mathrm{AlH}_{6}$. The high pressure, high temperature phase diagrams of $\mathrm{LiAlH}_{4}$ and $\mathrm{Li}_{3} \mathrm{AlH}_{6}$ are thus very closely linked.

The in situ DTA studies of Konovalov et al. were carried out as isobaric heating/cooling runs up to about $1000^{\circ} \mathrm{C}$ at pressures up to $4.5 \mathrm{GPa}$, and from the thermal anomalies observed a rather clear picture of the high temperature phase evolution on heating can be obtained, as shown in Fig. 1. At relatively low temperatures, 350-450 K, one or two weak exothermic DTA peaks were observed at all pressures, and these were assumed to arise from reactions with impurities, oxygen or water. Between 530 and $660 \mathrm{~K}$, depending on the pressure, a transformation was found into the tetragonal $\beta$ phase observed in earlier work [12]. The transformation was reported to be slow and to proceed over a rather wide range in temperature, $70-80 \mathrm{~K}$. The $\beta$ phase was again found to be metastable under ambient conditions if quenched from high pressure, and it should be emphasized that Fig. 1 is not an equilibrium phase diagram but rather a "transition map", valid for increasing temperature only. Ex situ X-ray diffraction studies confirmed that the $\beta$ phase had a tetragonal lattice. The structure could not be solved in detail, but the density of the $\beta$ phase 


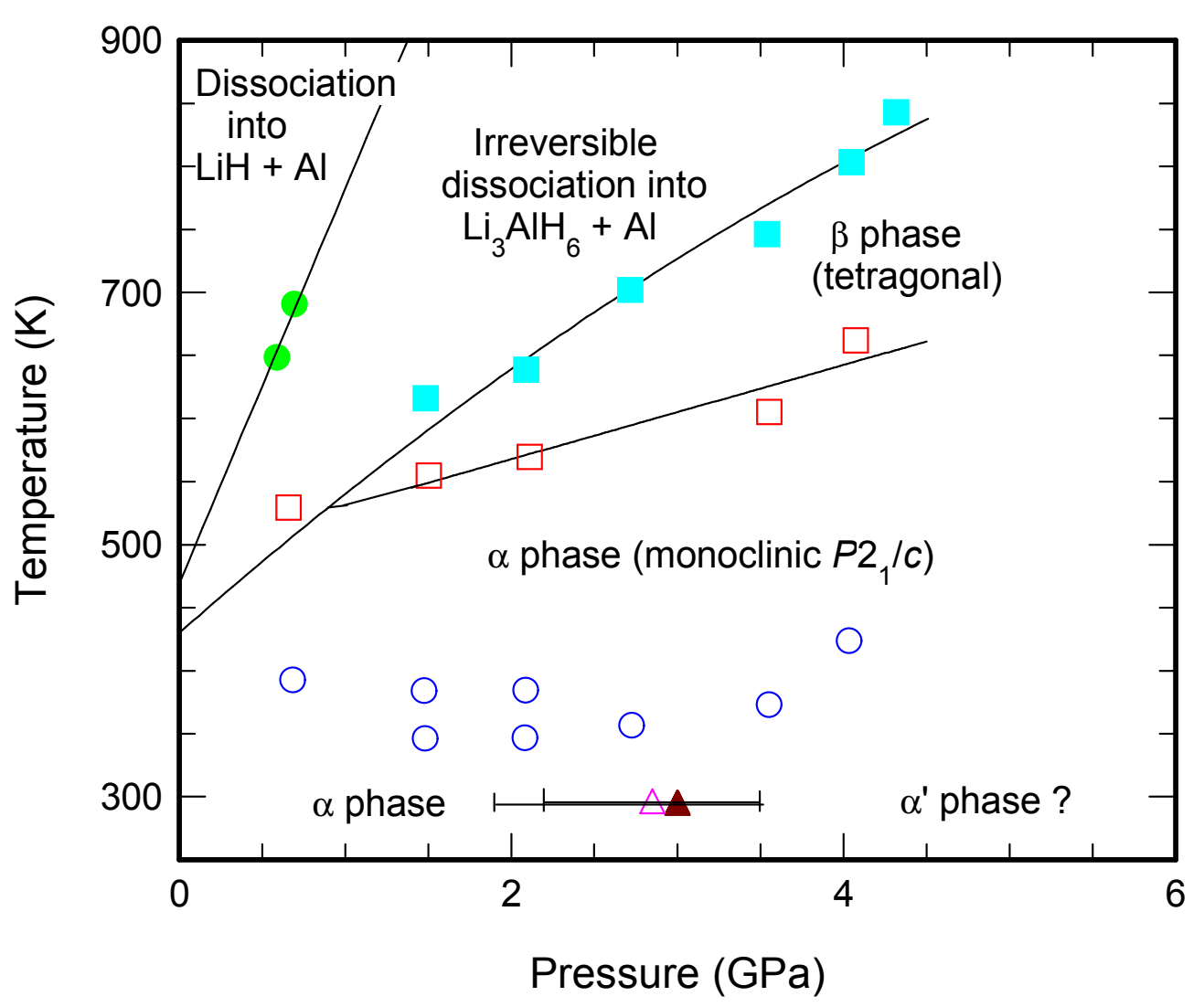

Fig. 1 Phase diagram for $\mathrm{LiAlH}_{4}$, drawn from literature data [14,16-20] for increasing temperature as discussed in the text. Squares and circles denote thermal anomalies observed by Konovalov et al. [14]; open circles are unidentified anomalies attributed to impurities. Open triangle Talyzin and Sundqvist [16,17], filled triangle Chellappa et al. [18,19]; bars show observed transition ranges. Phase boundaries have been redrawn as the best-fitted straight lines or, for the $\mathrm{Li}_{3} \mathrm{AlH}_{6}$ boundary, a parabolic curve through the zero-pressure point.

than that of the $\alpha$ phase and IR spectra again indicated that the coordination number of the Al increased from four in the $\alpha$ phase to six in the $\beta$ phase. The very large difference between the densities of the $\alpha$ and $\beta$ phases, the sluggishness of the $\alpha \rightarrow \beta$ transformation, and the observed change in coordination number indicate rather large differences between the structures of the two phases. Although the $\beta$ phase was metastable at room temperature, heating to $360-370 \mathrm{~K}$ at atmospheric pressure resulted in a transformation back to the $\alpha$ phase accompanied by a strong endothermal effect, as observed earlier [12,13]. As mentioned above, further heating to $600-850 \mathrm{~K}$ under pressure resulted in a conversion of the material into a mixture of $\mathrm{Li}_{3} \mathrm{AlH}_{6}$ and metallic aluminium, as indicated by Eq. 1. For comparison, at atmospheric pressure this reaction occurs near $430 \mathrm{~K} \mathrm{[4]} \mathrm{and} \mathrm{the} \mathrm{phase} \mathrm{line} \mathrm{has} \mathrm{been} \mathrm{smoothly} \mathrm{extrapolated} \mathrm{to} \mathrm{this} \mathrm{temperature} \mathrm{at} \mathrm{zero} \mathrm{pressure.}$ Under high pressure conditions the reaction is irreversible, not only because the formation of $\mathrm{LiAlH}_{4}$ from $\mathrm{Li}_{3} \mathrm{AlH}_{4}$ seems to be thermodynamically forbidden [7,8] but also because the hydrogen formed is quickly lost by diffusion or reactions with pressure media. Once this reaction has occurred the future evolution of the sample will therefore continue according to the phase diagram of $\mathrm{Li}_{3} \mathrm{AlH}_{6}$, which will be discussed further below. It should be noted that the phase boundaries given by Konovalov et al. from their in situ DTA studies are only approximate, because the reactions were smeared over wide ranges in temperature, and the experimental data indicate the positions of the most intense peaks. Also, in the earlier study by the same group [12] partial formation of the $\beta$ phase is reported already at $373 \mathrm{~K}$ at $7 \mathrm{GPa}$, far below the phase line shown in Fig. 1, and partial 
formation of the " $\gamma$ " phase (i.e., dissociation into $\mathrm{Li}_{3} \mathrm{AlH}_{6}$ ) is observed at $773 \mathrm{~K}$, again well below the corresponding line in Fig. 1.

The early work discussed above did not give any indications about the existence of a structural phase transition at low pressures near room temperature. Still, after the prediction by Vajeeston et al. [3,15] that at $293 \mathrm{~K}, \mathrm{LiAlH}_{4}$ should transform from its monoclinic $P 2_{1} / c$ $\alpha$ phase into first the tetragonal $I 4_{1} / a \alpha-\mathrm{NaAlH}_{4}$ structure at $2.6 \mathrm{GPa}$, corresponding to an increase in the density by about $17 \%$, then into an orthorhombic Pnma structure at $33.8 \mathrm{GPa}$, Raman studies under pressure clearly showed strong anomalies in the spectra obtained in the range $2.5-3 \mathrm{GPa}$ [16-19]. These anomalies were reversible and the initial spectrum was always recovered when pressure was released, although rapid pressure quenching could preserve at least partially the high pressure phase down to well below $1 \mathrm{GPa}[16,19]$. Close analysis of the change in the Raman spectrum at the transition showed, however, that the structure of the new high-pressure phase was not compatible with the tetragonal structure predicted by Vajeeston et al.

To identify the new structure and, if possible, reconcile the very different pictures given by these results and by the phase diagram of Konovalov et al. [14], Pitt et al. [20] recently carried out a very careful structural study on $\mathrm{LiAlD}_{4}$ by neutron diffraction up to $7.15 \mathrm{GPa}$, using Fluorinert as hydrostatic pressure medium. The results clearly showed that at room temperature, the sample remained in its original $\alpha-\mathrm{LiAlH}_{4}$ monoclinic $P 2_{1} / c$ structure at all pressures. However, the compression was not uniform and the unit cell changed its relative dimensions very strongly, with a clear break in the slope of lattice parameter $b$ versus pressure near $3 \mathrm{GPa}$. The structure is clearly very soft in the $\mathrm{b}$ direction at low pressures, and up to $3 \mathrm{GPa}$ the unit cell volume dropped by about $20 \%$. At $3 \mathrm{GPa}$ the lattice stiffness suddenly increases, and the final volume reduction up to $7 \mathrm{GPa}$ is about $27 \%$. This distortion of the unit cell leads to an increased distortion of the $\mathrm{AlH}_{4}$ tetrahedra above $2.5 \mathrm{GPa}$, which is the probable reason for the observed anomalies in Raman spectra [16-19]. Heating to $333 \mathrm{~K}$ at $7 \mathrm{GPa}$ resulted in the appearance of several new peaks identified as originating from the high-temperature $\beta$ phase, in general agreement with the report by Bulychev et al. [12] that a two-phase material can be created even by slight heating at $7 \mathrm{GPa}$ but in less good agreement with the phase diagram of Konovalov et al. [14] (Fig. 1; see also comment above). Under the high pressure conditions used, Rietveld fits showed that both structures were strongly distorted. Although the dominant $\alpha$ phase (estimated as $63 \%$ by volume) could still be indexed as monoclinic $P 2{ }_{1} / c$ at 7 $\mathrm{GPa}$, the $\mathrm{AlH}_{4}$ tetrahedra were found to be distorted such that the Al atoms were actually lying in basically the same plane as three hydrogen atoms. For the $\beta$ phase, the best fit was obtained with a monoclinic lattice with symmetry $I 2 / b$ which could be described as a slightly distorted version of the tetragonal $I 4_{1} / a$ structure predicted by Vajeeston et al. [3] to exist between 2.6 and $33.8 \mathrm{GPa}$. Pitt et al. speculate that the observed $I 2 / b$ structure is caused by mechanical strain in the two-phase mixture and will change into the predicted $I 4_{1} / a$ structure when the transformation into the $\beta$ phase is complete. On decompression and cooling the structure returned completely to the initial $\alpha$ phase.

In Fig. 1, the $\beta$ phase has tentatively been labeled "tetragonal" in accordance with the identification by Konovalov et al., since the work of Pitt et al. [20] leaves open the question whether the pure phase is $I 4_{1} / a$ or $I 2 / b$. Two alpha phases, $\alpha$ and $\alpha$, have been indicated, corresponding to the low-pressure $\alpha$ phase and to the high pressure $\alpha^{\prime}$ phase with strongly deformed $\mathrm{AlH}_{4}$ tetrahedra [20], respectively. It may, of course, be speculated whether some of the unidentified anomalies observed by Konovalov et al. (open circles) might also be connected with the lattice deformation associated with the Raman anomalies observed [16-19] on the boundary between phases $\alpha$ and $\alpha$ '.

Heating of $\mathrm{LiAlH}_{4}$ leads to the irreversible formation of $\mathrm{Li}_{3} \mathrm{AlH}_{6}$. The phase diagram of this material was also studied by Konovalov et al. [14], using both $\mathrm{LiAlH}_{4}$ and $\mathrm{Li}_{3} \mathrm{AlH}_{6}$ as starting materials. The phase relations found were the same, irrespectively of the starting material. At ambient conditions several structures have been reported for $\mathrm{Li}_{3} \mathrm{AlH}_{6}$, but recent work reports the structure of $\alpha-\mathrm{Li}_{3} \mathrm{AlH}_{6}$ as rhombohedral with symmetry $R \overline{3}[21,22]$. The in situ DTA studies of Konovalov et al. [14] showed 


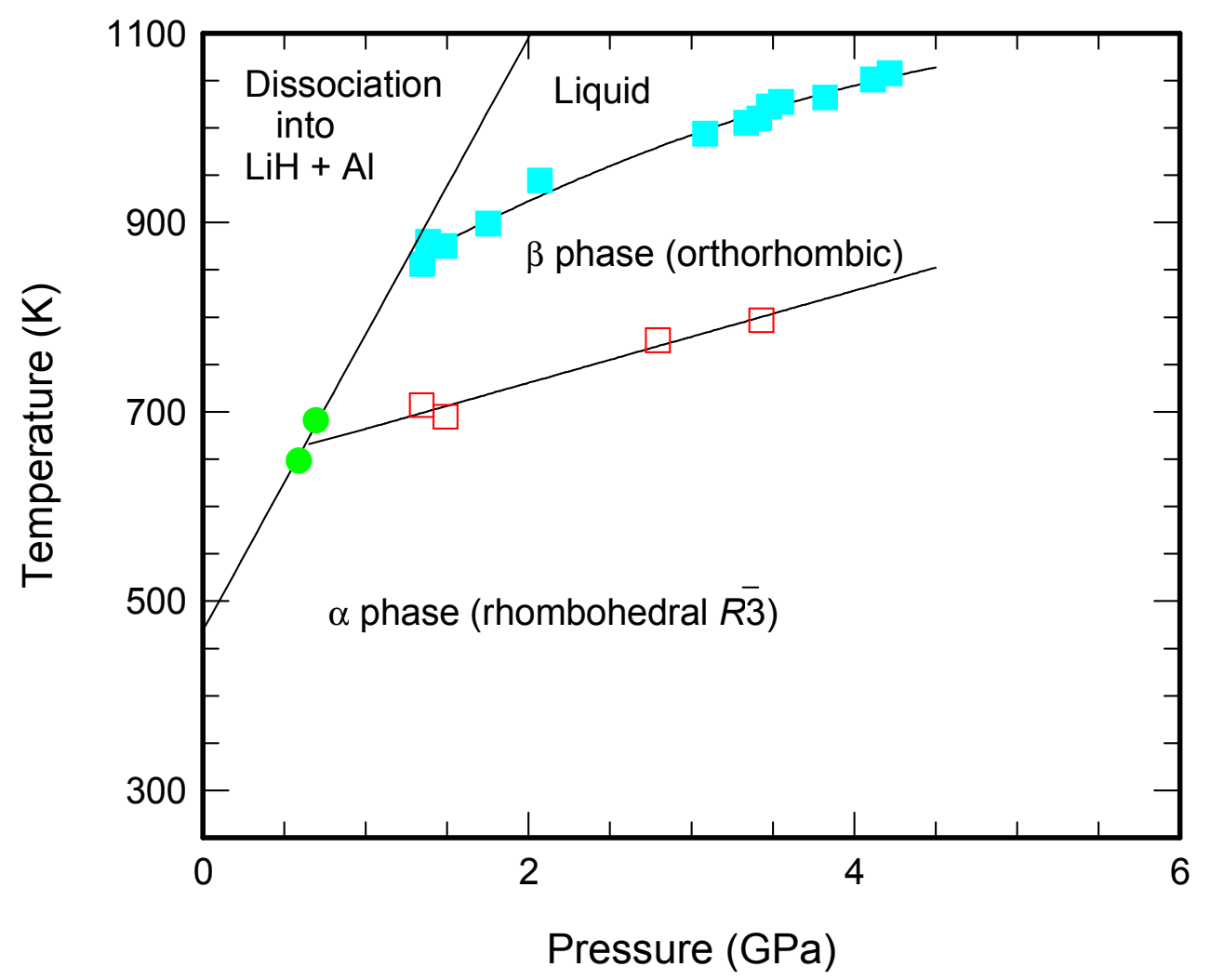

Fig. 2. Phase diagram for $\mathrm{Li}_{3} \mathrm{AlH}_{6}$, drawn from the data of Konovalov et al. [14]. Squares and circles denote positions of DTA anomalies observed. Phase boundaries have been redrawn as best fit straight lines or, for the liquid-solid boundary, a best fit parabolic curve. In addition, a cubic Ia $\overline{3}$ phase is observed at room temperature and very high pressure [25].

that the low-temperature phase transformed into a high-temperature phase at temperatures between 650 and $800 \mathrm{~K}$, depending on pressure. The high temperature phase was identified ex situ as an orthorhombic $\beta$ phase observed earlier [23] by X-ray diffraction studies on metastable material brought back from high pressure - high temperature conditions. The metastable $\beta$ phase transformed back to the $\alpha$ phase on heating to $350-370 \mathrm{~K}$ at atmospheric pressure. On heating to above $850-1100 \mathrm{~K}$ under pressures above $1 \mathrm{GPa}, \mathrm{Li}_{3} \mathrm{AlH}_{6}$ was observed to melt reversibly. Fig. 2 shows a phase diagram up to $6 \mathrm{GPa}$ for $\mathrm{Li}_{3} \mathrm{AlH}_{6}$. The transition lines are drawn from the data of Konovalov et al.; melting is reversible, but the $\alpha \rightarrow \beta$ line is valid for increasing temperature only. Again, because of the large hysteresis effects observed, this is not an equilibrium phase diagram but rather a transformation map, showing which reactions occur under what conditions on increasing temperature at constant pressure.

Further high-pressure phases of $\mathrm{Li}_{3} \mathrm{AlH}_{6}$ have been predicted theoretically and also in one case observed in experiments. Vajeeston et al. [24] predicted that the structure should evolve under high pressure at room temperature in a sequence of four different phases up to $90 \mathrm{GPa}$. Here, we call the three predicted high-pressure structures phases I, II, and III, to distinguish them from the lowpressure phases already discussed. The three transformations should occur from the rhombohedral $R \overline{3} \alpha$ phase into a cubic $I a \overline{3}$ phase I at $18.6 \mathrm{GPa}$, then into another cubic $F d \overline{3}$ phase II at 28.9 $\mathrm{GPa}$, and finally into orthorhombic Pna2 $2_{1}$ phase III at $68.8 \mathrm{GPa}$. It is noted that the four roomtemperature phases have very similar energies, that the volume changes at the transitions should be very small, and that it might be possible to stabilize at least phases I and II at atmospheric pressure. Very recently, Kumar et al. carried out a structural study on $\mathrm{Li}_{3} \mathrm{AlH}_{6}$ up to $27 \mathrm{GPa}$ at room temperature [25], and were able to verify the existence of a cubic $I a \overline{3}$ phase, corresponding to the predicted [24] phase I, at high pressures. The transformation from the $\alpha$ phase started near 10.6 GPa 
but the transition was sluggish and some lines for the $\alpha$ phase remained up to $17 \mathrm{GPa}$. The experimental volume change at the transition was about $10 \%$, significantly larger than theoretically predicted. Kumar et al. also carried out total energy calculations and found a theoretical transition pressure of $10.0 \mathrm{GPa}$, in excellent agreement with the experimental results. According to these calculations, the second (I-II) transformation should occur near $23.5 \mathrm{GPa}$, again somewhat lower than predicted by Vajeeston et al. [24].

Finally, Konovalov et al. [14] also observed the final dissociation of $\mathrm{Li}_{3} \mathrm{AlH}_{6}$ into $\mathrm{LiH}$ and metallic Al under pressure. Only two points were given on their phase diagram, but the process is known to take place near $470 \mathrm{~K}$ at atmospheric pressure [4]. Ke and Chen [8] calculated the equilibrium pressure for this process, but the agreement between their result and the high-pressure data of Konovalov et al. is not very good. For completeness, the experimental breakdown line has been inserted into Figures 1 and 2.

Sodium Aluminium Hydrides. Because of its ability to store hydrogen in a reversible cycle, $\mathrm{NaAlH}_{4}$ has also been quite well investigated in recent years. Under atmospheric conditions it forms a tetragonal lattice structure with symmetry $I 4_{1} / a$ ( $\alpha$ phase), containing somewhat distorted $\mathrm{AlH}_{4}$ tetrahedra. $\mathrm{NaAlH}_{4}$ has been much less investigated under high pressure than $\mathrm{LiAlH}_{4}$. Like the latter material, it was investigated already by Bulychev et al. [12], but it was found that treatment at $7 \mathrm{GPa}$ at temperatures up to $600^{\circ} \mathrm{C}$ did not result in the formation of any new high-pressure structures metastable under ambient conditions.

More recently, Vajeeston et al. [25] used total energy calculations to predict that $\mathrm{NaAlH}_{4}$ should transform into an orthorhombic structure (symmetry $C m c 2_{1}$ ) near $6.4 \mathrm{GPa}$. The predicted transformation should involve a change in the coordination number of the Al atom from 4 to 6 but only a small change in volume, by about 4 percent. (The calculated compression behaviors of all alkali metal $\mathrm{MAlH}_{4}$ compounds up to $40 \mathrm{GPa}$ have been shown in graphical form by Ravindran et al. [15]). Later experimental studies have indeed verified the existence of structural transformations in $\mathrm{NaAlH}_{4}$ at high pressures, but at higher pressure and into a different structure. An early in situ high pressure study by Nakano et al. [26], using both X-ray diffraction and Raman spectroscopy, and using $\mathrm{He}$ as hydrostatic pressure transmitting medium, showed clear evidence for structural transitions near 12 and $20 \mathrm{GPa}$ at room temperature, and the Raman data indicated a further transformation, possibly into an amorphous state, above $30 \mathrm{GPa}$. Although they were not able to identify any of the new high-pressure phases, the X-ray diffraction pattern for new phase observed between 12 and $20 \mathrm{GPa}$ was not compatible with the predicted orthorhombic structure. However, the measured bulk modulus of the $\alpha$ phase, $\mathrm{B}_{0}=20 \mathrm{GPa}$, was in excellent agreement with the value 19.3 calculated by Vajeeston et al. [25].

The existence of a structural phase transition near $12 \mathrm{GPa}$ has been verified by several later in situ studies. Clear signs of a structural transformation are found in Raman spectra by both Talyzin and Sundqvist [27] (transition starting between 12.9 and $14 \mathrm{GPa}$ ) and by Kumar et al. [28] (starting between 12 and $14 \mathrm{GPa}$ ), with the two phases coexisting over a range of 3-5 GPa. Kumar et al. also carried out in situ X-ray diffraction studies up to $27 \mathrm{GPa}$ on both $\mathrm{NaAlH}_{4}$ and $\mathrm{NaAlD}_{4}$, and for both materials a structural transformation was observed to start above $13 \mathrm{GPa}$. The initial bulk modulus of the $\alpha$ phase was found to be $\mathrm{B}_{0}=27 \mathrm{GPa}$, significantly higher than found in earlier work [26], and the transformation was associated with a change in volume by about 12 percent. Because of the reactivity of $\mathrm{NaAlH}_{4}$ neither of these X-ray and Raman studies used a pressure transmitting medium, but this is usually not be a serious problem in studies of soft, plastic materials. The structure of the high-pressure $\beta$ phase above $13 \mathrm{GPa}$ was identified as monoclinic with symmetry $P 2_{1} / c$. Kumar et al. also carried out total energy calculations and 


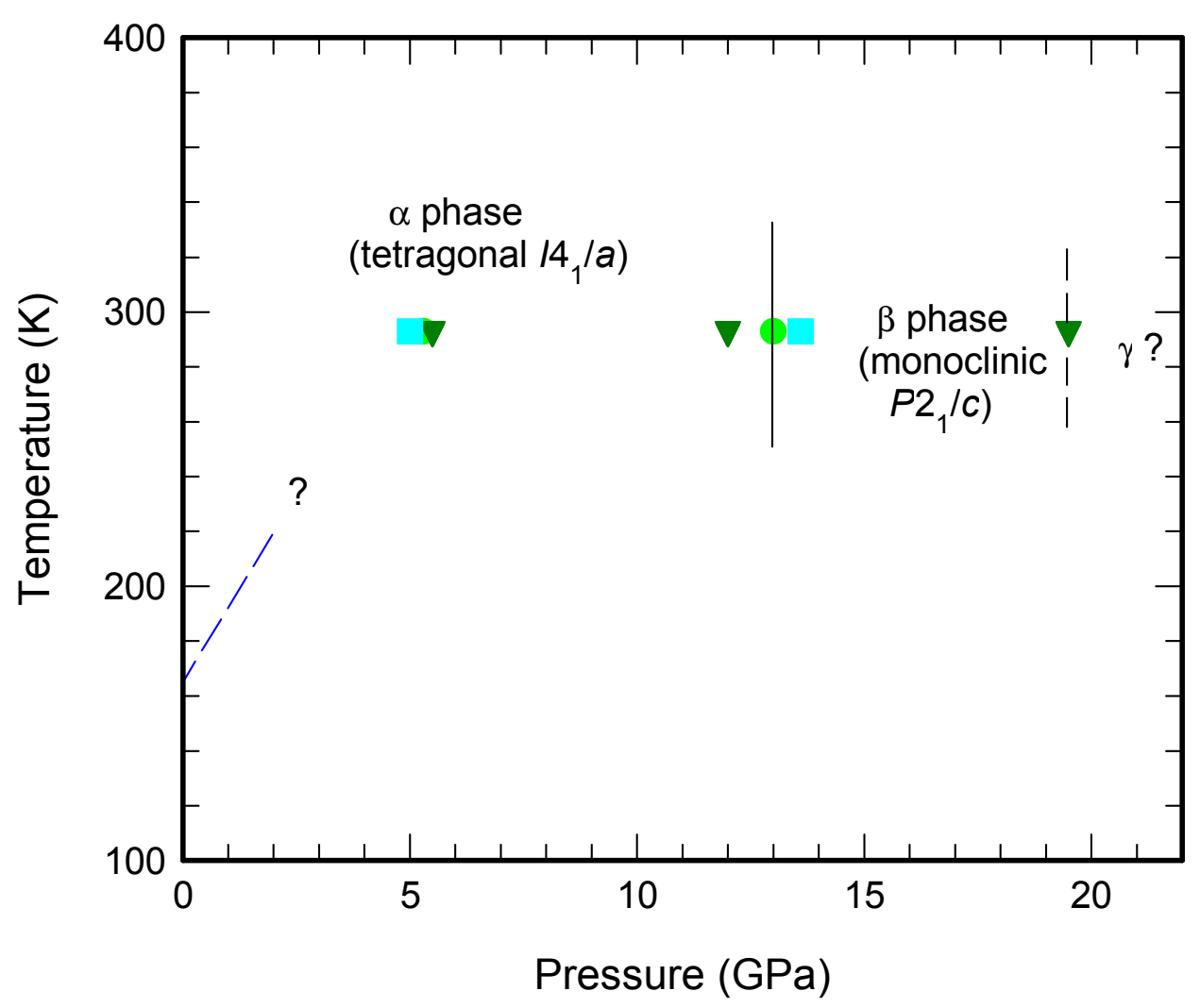

Fig. 3 Preliminary phase diagram for $\mathrm{NaAlH}_{4}$. Symbols denote anomalies observed in Raman or Xray diffraction work: Triangles Nakano et al. [26], squares Talyzin and Sundqvist [27], dots Kumar et al. [28]. Dashed lines indicate unconfirmed transformations at $0-5$ and $20 \mathrm{GPa}$, short solid vertical line indicates structural transformation boundary with unknown slope.

found that this structure indeed had the lowest energy of the structures tested at high pressures, and the calculated enthalpy showed a transition pressure near $14 \mathrm{GPa}$, in excellent agreement with the experiments. Both Kumar et al. [28] and Talyzin and Sundqvist [27] find extremely large hysteresis effects in the structural evolution with pressure. The monoclinic $\beta$ phase is formed when the pressure exceeds about $13 \mathrm{GPa}$, but on pressure release this structure is stable to surprisingly low pressures. The low-pressure $\alpha$ phase does not reappear until close to $3 \mathrm{GPa}$, and the pressure hysteresis is thus of the order of $10 \mathrm{GPa}$. It is also interesting to note that the structural phase transition reported by Nakano et al. near $20 \mathrm{GPa}$ [26] was not observed in the experiments of Kumar et al. One possible explanation is that the small changes in the Raman spectra (peak shifts) and the $\mathrm{X}$-ray diffraction diagrams (changes in relative peak intensities, disappearance of peaks) observed by Nagano et al. are due to gradual changes in the structure with increasing pressure, and that the 20 $\mathrm{GPa}$ transformation thus does not exist. Another possibility is that the different experimental conditions might play a role: Nakano et al. used He as a hydrostatic pressure medium, while Kumar et al. did not use any pressure-transmitting medium. In any case, further studies at pressures exceeding $20 \mathrm{GPa}$ are necessary to see if further phase transformations exist for this material.

Small anomalies are visible in the Raman spectra for $\mathrm{NaAlH}_{4}$ measured by several groups in the range $2-5 \mathrm{GPa}$ at room temperature [17, 26-28], and small anomalies can also be observed in some X-ray results [26] in the same range. The Raman anomalies show some hysteresis, but the lowpressure state is always recovered below about $1.5 \mathrm{GPa}$ [27]. A low temperature thermal conductivity study under pressures up to $2 \mathrm{GPa}$ also showed very small anomalies in the thermal properties $[29,30]$ at temperatures which shifted systematically with pressure to extrapolate to about $160 \mathrm{~K}$ at zero pressure and to about $4.5 \mathrm{GPa}$ at room temperature. The source of these small 
anomalies has not been finally identified, but some minor structural change such as a small deformation or reorientation of the $\mathrm{AlH}_{4}$ tetrahedra might be involved.

Except for the very small anomalies mentioned above, the thermal conductivity data obtained by Sundqvist and Andersson [29, 30] showed no evidence for any other phase transitions in the pressure range up to $2 \mathrm{GPa}$ at temperatures between 100 and $300 \mathrm{~K}$. The low temperature structural phase diagram of $\mathrm{NaAlH}_{4}$ is thus very simple, containing only two confirmed phases as indicated in Figure 3. At high pressure there might exist another phase above $20 \mathrm{GPa}$, and the dashed line (and question mark) and the symbols at low pressures indicate a small possibility that there exists an additional low temperature phase which differs only marginally in its structure from the $\alpha$ phase, but the evidence for its existence are very weak, as discussed above. Neither the melting of $\mathrm{NaAlH}_{4}$ nor its conversion into $\mathrm{Na}_{3} \mathrm{AlH}_{6}$ (see Eq. 1), which at atmospheric pressure occurs near $393 \mathrm{~K}$, have been observed under high pressure, and the phase diagram shown thus evidently needs to be revised by further measurements both at high temperature and at high pressure.

The compound $\mathrm{Na}_{3} \mathrm{AlH}_{6}$ is an important intermediate product in the release of hydrogen from $\mathrm{NaAlH}_{4}$ and can also, like $\mathrm{Li}_{3} \mathrm{AlH}_{6}$, be used on its own as a source of hydrogen (Eq. 1). On heating, $\mathrm{Na}_{3} \mathrm{AlH}_{6}$ transforms near $525 \mathrm{~K}$ from its room temperature monoclinic $P 2_{1} / n \alpha$ phase into a high temperature $\beta$ phase, shown by Bastide et al. [31] to have a face centered cubic $F m \overline{3} m$ structure. Bastide et al. report that the $\alpha-\beta$ transition is reversible and that melting occurs at $568 \mathrm{~K}$, although some degree of decomposition into $\mathrm{NaH}$ and metallic $\mathrm{Al}$ occurs above $265 \mathrm{~K}$ (Eq. 1). The same group also carried out two high-pressure experiments at $3.5 \mathrm{GPa}$, with the samples analyzed ex situ after heat treatment. A sample treated at $623 \mathrm{~K}$ showed no structural changes, while a sample treated at $1173 \mathrm{~K}$ was found to contain metastable $\beta$ phase with a morphology showing that the sample had melted under pressure. The metastable phase could be transformed into the $\alpha$ phase by grinding or by heating to above $410 \mathrm{~K}$.

No experimental data are available at room temperature, but Vajeeston et al. [31] have recently predicted a transformation from the monoclinic $P 2_{1} / n \alpha$ phase, stable at atmospheric pressure, into an orthorhombic $\mathrm{Pbcm}$ structure near $20 \mathrm{GPa}$. The transition is associated with a small change in volume by about $4.5 \%$.

Since only two pressure-temperature points have been experimentally investigated little is known about the details of the phase diagram, and the actual phase boundaries need to be verified and mapped under pressure at both high and low temperatures.

Other Alkali Metal Aluminium Hydrides. For the heavier alkali metal alanates, $\mathrm{KAlH}_{4}$, $\mathrm{RbAlH}_{4}$ and $\mathrm{CsAlH}_{4}$, and their $\mathrm{M}_{3} \mathrm{AlH}_{6}$ counterparts, little is known about the high-pressure phase diagrams. There has been some recent interest in $\mathrm{KAlH}_{4}$ since this material was reported to reversibly store and release hydrogen without the help of catalysts [33], but the low weight fraction of hydrogen makes it less attractive as a storage material. The reaction is very similar to that for $\mathrm{NaAlH}_{4}$ given in Eq. 1, except that the two steps occur at higher temperatures near $573 \mathrm{~K}$ and 613 $\mathrm{K}$, respectively $[33,34]$. The high temperature part of the phase diagram of $\mathrm{KAlH}_{4}$ should thus be somewhat similar to those of the $\mathrm{MAlH}_{4}$ materials discussed above, with a transformation into $\mathrm{K}_{3} \mathrm{AlH}_{6}$ at high temperature also under pressure. Similar results may be expected for the other heavy $\mathrm{MAlH}_{4}$ compounds.

Regarding the very-high-pressure structural evolution near room temperature, there are a small number of theoretical predictions. $\mathrm{KAlH}_{4}$ is predicted to be stable under pressure and to keep its orthorhombic Pnma structure at least up to $100 \mathrm{GPa}[15,35]$, while the closely related $\mathrm{K}_{3} \mathrm{AlH}_{6}$ is predicted to have two structural transformations under pressure [36]. The monoclinic $P 2{ }_{1} / n \alpha$ phase should first transform near $53 \mathrm{GPa}$ into a tetragonal $14 / \mathrm{mmm}$ structure, then near $60 \mathrm{GPa}$ into a high pressure Pnnm orthorhombic structure. $\mathrm{RbAlH}_{4}$ is predicted to be the least compressible of the $\mathrm{MAlH}_{4}$ compounds and to transform near $7 \mathrm{GPa}$ from its ambient pressure orthorhombic Pnma structure into a different orthorhombic $\mathrm{Cmc2}_{2}$ phase with a relatively large volume change of 12 percent [15]. Finally, $\mathrm{CsAlH}_{4}$ is predicted to be the most compressible of these compounds and to 
have two phase transitions under pressure, first from its orthorhombic Pnma $\alpha$ phase to tetragonal $I 4_{1} / a$ near $4 \mathrm{GPa}$, then into the orthorhombic $C m c 2_{2}$ structure near $8 \mathrm{GPa}$ [15]. These transitions should be associated with volume changes of about 4 and 9 percent, respectively.

Several mixed $\mathrm{M}_{3} \mathrm{AlH}_{6}$ compounds have also been observed experimentally or shown theoretically to be stable under ambient conditions. The compounds $\mathrm{Na}_{2} \mathrm{LiAlH}_{6}, \mathrm{~K}_{2} \mathrm{NaAlH}_{6}$, and $\mathrm{K}_{2} \mathrm{LiAlH}_{6}$ all crystallize in the face centered cubic $F m \overline{3} m$ structure at atmospheric pressure [36], but nothing is yet known about possible high-pressure phases of these materials.

\section{Alkali Metal Borohydrides}

The alkali metal borohydrides contain very high weight fractions of hydrogen, up to 18 percent in $\mathrm{LiBH}_{4}$. However, thermal hydrogen release from this material only occurs above $650 \mathrm{~K}$, which is rather high for practical applications. The hydrogen is most easily released by reaction with water, but this reaction is not easily controlled and also results in a rest product, which must be removed. Recent studies show that hydrogen can actually also be stored and released reversibly by thermal cycling, but without a catalyst the rehydrogenation occurs under quite unfavorable conditions, above 150 bar $\mathrm{H}_{2}$ pressure near $870 \mathrm{~K}$ [37]. Still, the interest in the borohydrides has been high in recent years, and the high-pressure structural phase diagrams of several of these materials are now reasonably well known.

Lithium Borohydrides. $\mathrm{LiBH}_{4}$ is unique among the borohydrides in having an orthorhombic Pnma structure (phase II) at room temperature and atmospheric pressure, which on heating transforms near $380 \mathrm{~K}$ into a high temperature phase I whose structure has been the subject of some discussion. (For $\mathrm{LiBH}_{4}$ the notation I, II, III.... will be used in order to simplify a comparison with literature data.) Although diffraction experiments on both powders [38] and single crystals [39] agree that the structure of phase I is hexagonal with $P 6_{3} m c$ symmetry, calculations usually show this structure to be unstable $[40,41]$ and other structures have been predicted theoretically. $\mathrm{LiBH}_{4}$ is also unique in that its structural pressure-temperature phase diagram was well investigated already by Pistorius in 1974 [42] up to $4.5 \mathrm{GPa}$ and $820 \mathrm{~K}$ using DTA. He found a phase diagram containing five different phases, but the actual lattice structures were only known for the two phases found at atmospheric pressure. Because the high temperature phase $I$ is denser than the room temperature phase II the phase boundary between these two phases has a negative slope. At room temperature, a transformation into phase III (with unknown structure) occurs already near $0.7 \mathrm{GPa}$.

The recent interest in these materials for hydrogen storage sparked a number of theoretical predictions of possible high-pressure structures. Łodziana and Vegge [40] predicted a monoclinic $C c$ structure both at high temperature and at high pressures above $3 \mathrm{GPa}$, in direct contradiction to the experimental results discussed above, while Frankcombe et al. [41] predict first a transition into monoclinic $P 2_{1} / c$ near $1 \mathrm{GPa}$ before the monoclinic $C c$ structure appears above $2 \mathrm{GPa}$. Vajeeston et al. [43] instead predicted a transformation near $6.2 \mathrm{GPa}$ into a tetragonal $P \overline{4} 2_{1} c$ structure.

To test these predictions and to gain more insight into possible new high-pressure structures of the borohydrides, the phase diagram of $\mathrm{LiBH}_{4}$ has been experimentally investigated in great detail by several methods during the last few years [30,44-47]. As a result, the phase diagram given by Pistorius has had to be slightly revised and the structures of all known phases have been identified in detail. Interestingly, none of the high-pressure phases identified experimentally [46, 47] has had any of the high-pressure structures predicted by theory.

The first of these recent investigations verified the low temperature part of the phase diagram given by Pistorius [42] and extended it to $100 \mathrm{~K}$ at pressures below $1 \mathrm{GPa}$ [44,45]. Raman spectroscopy clearly verified the existence of a transition between the low-pressure phase II and the high-pressure phase III near $0.75 \mathrm{GPa}$, and both this transition and the I-II transition were identified by DTA. The transformation 


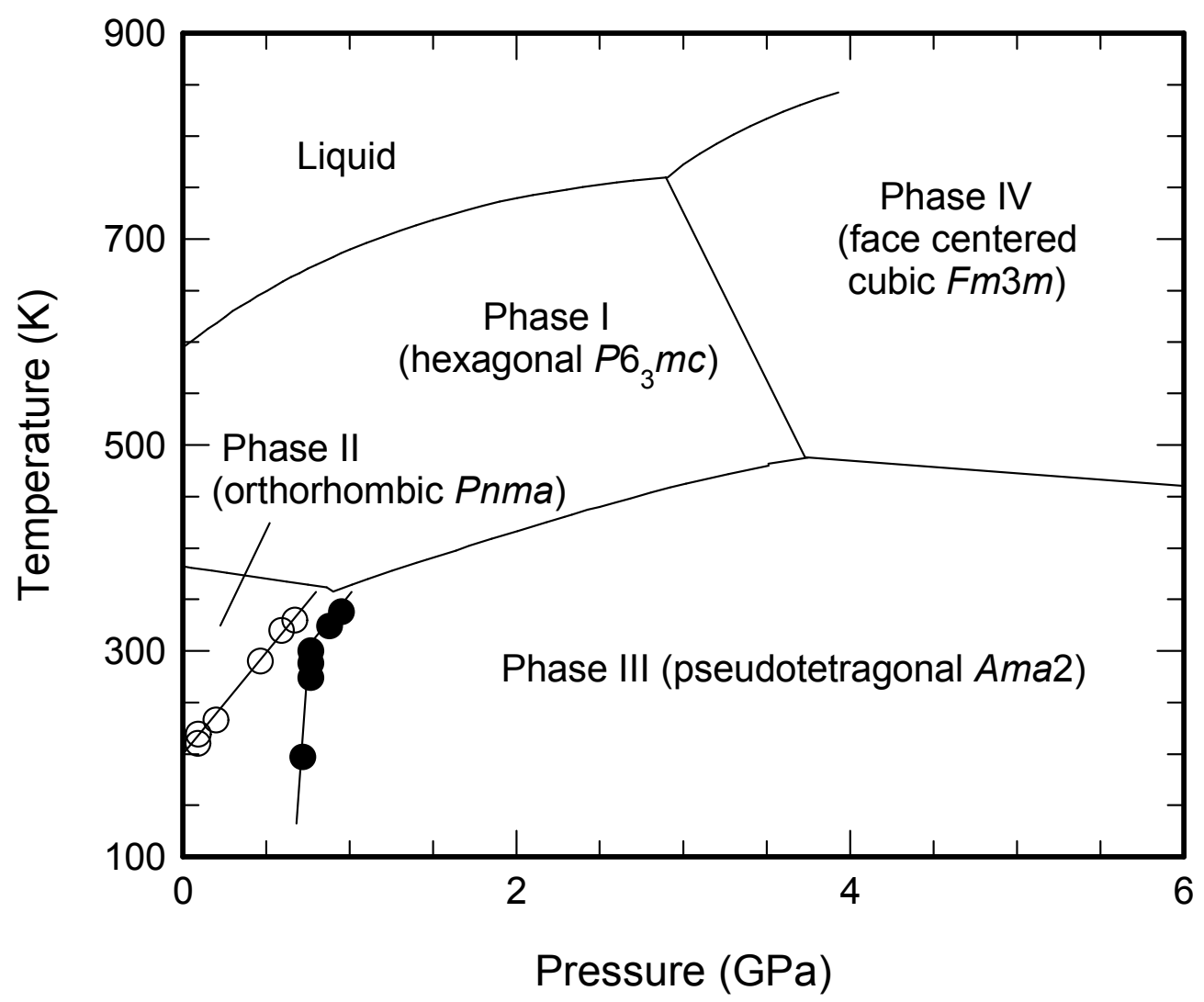

Fig. 4 Phase diagram of $\mathrm{LiBH}_{4}$, based on Refs. [42, 45, 47]. Most phase boundaries shown are believed to be equilibrium boundaries. For the I-III boundary, the hysteresis behaviour is shown by displaying experimental data (filled symbols transition I $\rightarrow$ III, open symbols transitions III $\rightarrow$ I).

between the low- and high-pressure phases II and III at and below room temperature was studied by DTA and by measurements of the thermal conductivity by a dynamic heat pulse method, and was shown to have a hysteresis behavior which depended very strongly on temperature [30, 45, 47]. Compression at room temperature gave a transformation into phase III near $0.78 \mathrm{GPa}$, and the transformation was reversible with a fairly large hysteresis of about $0.3 \mathrm{GPa}$. Similar values for the hysteresis were found also at higher temperatures [30, 47], but below room temperature the hysteresis increased rapidly because the II $\rightarrow$ III transformation began to occur at an only weakly temperature dependent pressure between 0.6 and $0.75 \mathrm{GPa}$ [45], indicating a significant energy threshold for the formation of phase III. However, the reverse transition line was still linear and extrapolated to about $190 \mathrm{~K}$ at atmospheric pressure. It was thus not possible to produce the highpressure phase at any pressure lower than about $0.6 \mathrm{GPa}$, but once formed it was stable to atmospheric pressure at any temperature below $190 \mathrm{~K}$. In situ X-ray diffraction studies were also carried out up to $9 \mathrm{GPa}$, but although a transformation was indeed observed the structure of the high-pressure phase could not be identified due to the low scattering powers of the light atoms involved and to the limited range of angles available. However, the data showed that the structure of phase III did not agree with any of the structures predicted by calculations $[40,41,43]$.

The structure of phase III was later identified by Filinchuk et al. [46] by in situ synchrotron X-ray diffraction experiments. The lattice was found to be pseudotetragonal with symmetry Ama2, and to have a very unusual, unexpected geometry with a square-planar coordination of the $\mathrm{BH}_{4}$ tetrahedra with four Li ions, a feature not observed for any other hydride. Density-functional theory (DFT) calculations were also carried out and confirmed that this structure had a lower energy than competing structures. The transition from phase II to phase III was observed to involve a rather large volume change by 6.6 percent, in good agreement with the value 5.6 percent found by Pistorius 
[42]. In addition to the known phase III, Filinchuk et al. also found a transition into a previously not observed face centered cubic $F m \overline{3} m$ phase, with orientationally disordered $\mathrm{BH}_{4}$ units, above 10 $\mathrm{GPa}$. The existence of such a dense, close-packed cubic high-pressure phase had been predicted by Pistorius [42] from the relative densities of the alkali metal borohydrides. However, the transformation into this phase was very slow, and although the transformation started near $10 \mathrm{GPa}$ only about 60 percent of the sample had yet transformed at the highest pressure studied, $18 \mathrm{GPa}$. The measured bulk moduli of the three phases II, III, and the $F m \overline{3} m$ phase were found to be $\mathrm{B}_{0}=14.4$, 23.2, and $26 \mathrm{GPa}$ (extrapolated to atmospheric pressure), and thus increasing with increasing density, as expected.

A later study [47] combined synchrotron X-ray diffraction at high temperature and pressure with thermal studies at lower pressures, and resulted in the structural phase diagram for $\mathrm{LiBH}_{4}$ shown in Figure 4. These studies showed that the high temperature, high-pressure "phase V" found by Pistorius was actually identical to the face centered cubic phase first identified at room temperature [46]. (In Figure 4, the "phase V" discussed by Pistorius and Filinchuk has been renamed "phase IV", since only four solid phases are known.) The DTA measurements of Pistorius always showed a double peak structure at the boundary between phases I and III in the phase diagram, and he thus deduced the existence of a "phase IV", appearing in a narrow interval of temperature and pressure between these two phases. The X-ray diffraction studies of Dmitriev et al. [47] were not able to find any evidence for such a phase, however. At all pressures and temperatures investigated only phases I and III were observed, either separate or co-existing over rather wide ranges in pressure and temperature. To investigate further, thermal conductivity and DTA studies were also carried out in this region, and both methods showed evidence of weak double anomalies when crossing the phase line. However, these double anomalies were probably caused by an unusual transition dynamics related to the particular structures of the material and not by the existence of an intermediate phase. A very careful structural analysis was successfully carried out for this unusual material, and both the structural relationships and the transition mechanisms were identified for all four phases observed. The two low-pressure phases I and II (hexagonal and orthorhombic, respectively) are closely related with structures based on a common hexagonal parent phase, and the transformation between these phases can thus easily occur by an atomic displacement mechanism. Similarly, the high-pressure phase II and IV (pseudotetragonal and cubic, respectively) are both close to cubic, and the transformation is rather easy. However, transformations between the two groups of structures involve both a reshuffling of the basic $\mathrm{ABAB}$ stacking of double cation-anion layers in the lowpressure phase into the $\mathrm{ABC}$ stacking related to cubic-like structures, or vice versa, a mechanism involving rather high energy barriers, and a reorientation of the $\mathrm{BH}_{4}$ units, which should be much faster. These features explain the strange properties observed at the II-III (very large, temperature dependent hysteresis) and I-III (double peak structure, indicating a two-step transformation) phase transitions. The same features probably also explain the anomalously small change in thermal conductivity with pressure observed in phase II [30,45], since the incipient transformation II $\rightarrow$ III should be connected with a soft acoustic phonon mode [47]. Both the phase diagram of $\mathrm{LiBH}_{4}$, shown in Figure 4, and the high-pressure properties of $\mathrm{LiBH}_{4}$ have thus by now been very well investigated and are generally well understood.

Sodium Borohydride. All borohydrides except $\mathrm{LiBH}_{4}$ share the same simple face centered cubic $F m \overline{3} m$ structure, based on alkali metal ions and orientationally disordered $\mathrm{BH}_{4}{ }^{-}$tetrahedra [48]. On cooling, $\mathrm{NaBH}_{4}$ transforms near $190 \mathrm{~K}$ into a tetragonal $P \overline{4} 2_{1} c$ phase by an orientational ordering of the $\mathrm{BH}_{4}$ units, and early resistance studies under pressure also showed low-pressure anomalies for both $\mathrm{LiBH}_{4}$ and $\mathrm{NaBH}_{4}$ [10]. Early high-pressure studies gave somewhat confusing results. Raman spectroscopy [17] indicated clear evidence for a reversible transition occurring between 11 and $15 \mathrm{GPa}$ on increasing pressure and 11 and $7 \mathrm{GPa}$ on decreasing pressure, but no anomalies below this. Early X-ray 


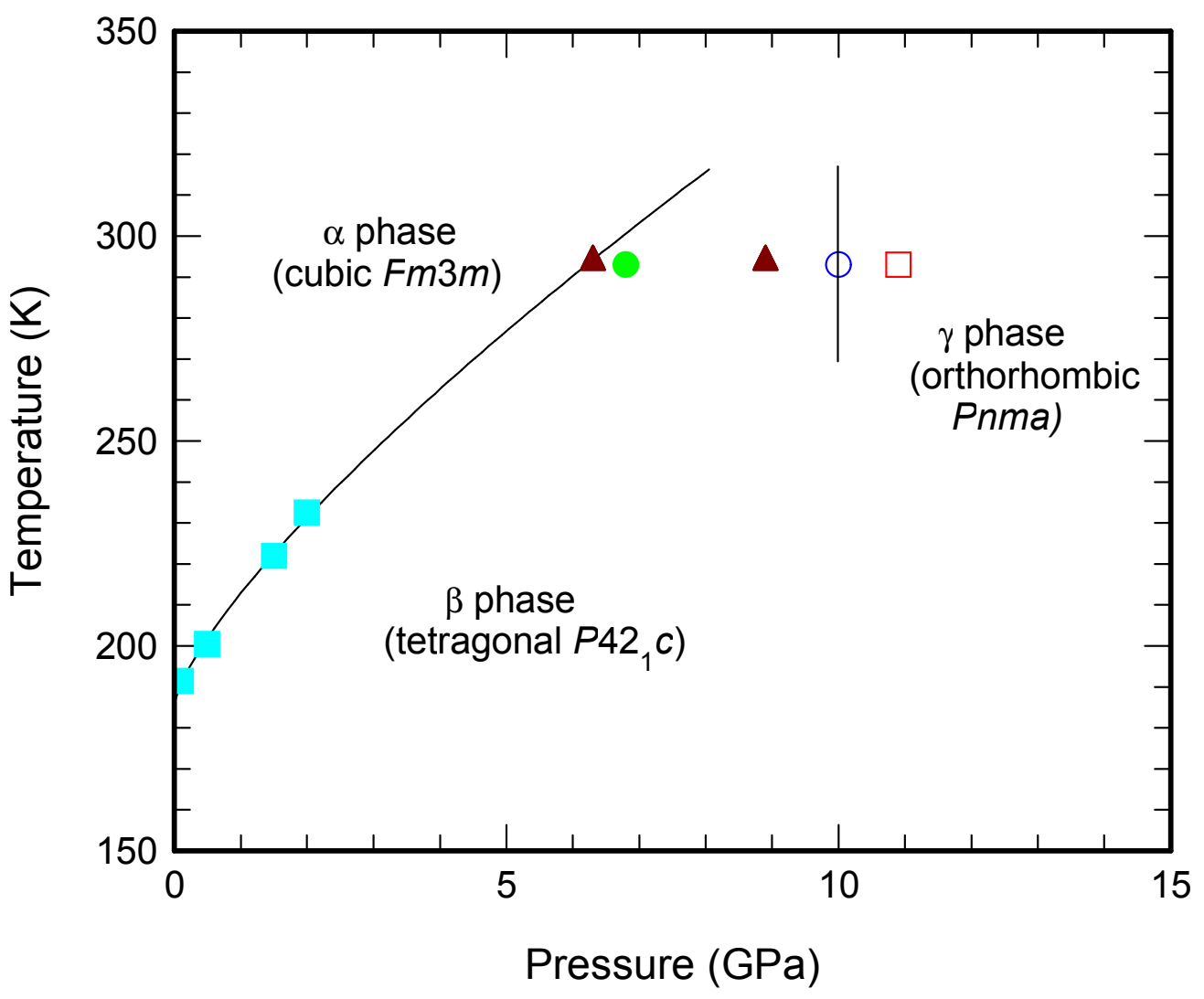

Fig. 5 Phase diagram for $\mathrm{NaBH}_{4}$. Symbols denote phase transition anomalies observed in Refs. [49] (dot), [50] (open square), [51] (triangles), [52] (circle), and [54] (filled squares).

diffraction studies, on the other hand, clearly showed a transformation near $6.8 \mathrm{GPa}$ [49], while no further transformations were observed up to $85 \mathrm{GPa}$. The high-pressure phase was tentatively identified as having a hexagonal unit cell. The two anomalies clearly arise from different transitions, however. As shown later by Araújo et al. [50], the low temperature cubic to tetragonal transition gave only very small anomalies in the Raman spectrum and this transition is thus not easily observed under pressure. The $6.8 \mathrm{GPa}$ transition was thus identified as this transformation, shifted from its normal $190 \mathrm{~K}$ by the applied pressure, and the transition near $10 \mathrm{GPa}$ was identified as a new high-pressure transformation. Total energy calculations predicted that the face centered cubic structure should transform first into the monoclinic $P 2_{1} / c \alpha$ phase of $\mathrm{LiAlH}_{4}$ near $19 \mathrm{GPa}$, then into the orthorhombic Pnma structure of $\mathrm{LiBH}_{4}$ phase II near $33 \mathrm{GPa}$, and the new high-pressure phase was thus tentatively identified as monoclinic $P 2_{1} / c$. However, later Kumar and Cornelius [51] carried out in situ X-ray diffraction work and deduced that the new phase instead had the orthorhombic Pnma structure. Kumar and Cornelius observed first the cubic to tetragonal transformation between 6.3 and $8.9 \mathrm{GPa}$, then a transition into an orthorhombic Pnma phase above $10 \mathrm{GPa}$. All transitions were completely reversible with a small hysteresis, and Kumar and Cornelius also give values for the bulk moduli of the cubic and orthorhombic phases as $\mathrm{B}_{0}=19.9$ and $31 \mathrm{GPa}$, respectively. Finally, the complete lattice structure of the orthorhombic phase, including atomic coordinates, was recently determined by Filinchuk et al. [52], again by in situ Xray diffraction studies. The lattice was found to be different from the theoretically predicted Pnma structure, having a $\mathrm{BaSO}_{4}$ type structure instead of the predicted $\mathrm{LiBH}_{4} \alpha$ structure.

To verify that the high-pressure tetragonal phase was, in fact, identical to the tetragonal $P \overline{4} 2_{1} c$ phase found at low temperature, Sundqvist and Andersson [54] carried out measurements of the thermal conductivity of $\mathrm{NaBH}_{4}$ between 100 and $300 \mathrm{~K}$ up to $2 \mathrm{GPa}$. The tetragonal to cubic phase transformation boundary could be very well defined up to $2 \mathrm{GPa}$ from the very large and clear 
anomalies found at the transitions, and the phase boundary could be extrapolated to agree very well with the transition found at room temperature above $6 \mathrm{GPa}$, as shown in the phase diagram displayed in Figure 5. More recently, Kim et al. [53] presented more detailed in situ structural data for the intermediate phase obtained by neutron diffraction measurements on $\mathrm{NaBD}_{4}$ and combined these with theoretical calculations to confirm that the structure was tetragonal. The results from these two investigations clearly show that the two tetragonal phases are indeed identical, and the phase diagram thus contains only a single tetragonal phase with symmetry $P \overline{4} 2_{1} c$. Lee et al. [55] have made an attempt to calculate the slope of this phase line using DFT, but the theoretical slope exceeds that found experimentally by a large factor.

Other Alkali Metal Borohydrides. As mentioned above, all heavier borohydrides have a face centered cubic $F m \overline{3} m$ structure at room temperature under atmospheric pressure [48], and all are believed to transform into lower symmetry phases on cooling. Like $\mathrm{NaBH}_{4}, \mathrm{KBH}_{4}$ transforms into a tetragonal structure at low temperature by orientational ordering of the $\mathrm{BH}_{4}$ units. For $\mathrm{KBH}_{4}$ the transition occurs near $76 \mathrm{~K}$ and the tetragonal structure is believed to have symmetry $P 4_{2} / n m c$, differing from the $P \overline{4} 2_{1} c$ phase of $\mathrm{NaBH}_{4}$ in the positions of the hydrogen atoms [43]. The very similar structures and phase relations of $\mathrm{NaBH}_{4}$ and $\mathrm{KBH}_{4}$ at atmospheric pressure suggest that the high pressure behaviors should also be similar, and a recent Raman study on $\mathrm{KBH}_{4}$ indeed showed evidence for a structural phase transformation between 6 and $6.9 \mathrm{GPa}$ [44]. Because the cubic to tetragonal transformation should give only weak anomalies in the Raman spectrum (see discussion of $\mathrm{NaBH}_{4}$ above), this transformation probably corresponds to a transformation into some other structure. Although the authors suggested that the most obvious candidate would be an orthorhombic structure similar to that observed in $\mathrm{NaBH}_{4}$ under pressure, the in situ X-ray diffraction data obtained were not sufficient to conclusively identify the structure. More recently, Kumar et al. [56] carried out an in situ synchrotron X-ray diffraction study in combination with in situ Raman spectroscopy. This investigation showed two-phase transformations in $\mathrm{KBH}_{4}$ under pressure, first a transformation near $3.8 \mathrm{GPa}$ from cubic $F m \overline{3} m$ into a tetragonal phase, identified as having symmetry $P \overline{4} 2_{1} c$, then into an orthorhombic Pnma phase between 6.2 and $10 \mathrm{GPa}$. Raman data were in excellent agreement with those of Sundqvist et al. [44], showing clear anomalies only for the transition into the orthorhombic phase. All phase transformations were reversible on pressure release, with only small hysteresis effects. The authors also carried out total energy calculations, which supported the identifications of the structures. The bulk modulus of the cubic phase was found to be $\mathrm{B}_{0}=16.8 \mathrm{GPa}$, and $\mathrm{KBH}_{4}$ is thus slightly more compressible than $\mathrm{NaBH}_{4}$, as expected.

The appearance of a tetragonal phase at low pressures in $\mathrm{KBH}_{4}$ raises some interesting questions. Kumar et al. [56] find $P \overline{4} 2{ }_{1} c$ symmetry, as for the tetragonal phase of $\mathrm{NaBH}_{4}$, while the known low temperature tetragonal phase of $\mathrm{KBH}_{4}$ has been identified to have $P 4_{2} / n m c$ symmetry [48]. From the results of their calculations, Kumar et al. suggest that the $P \overline{4}{ }_{1} c$ phase is more stable at room temperature and should evolve into $P 4_{2} / n m c$ on cooling. The low temperature phase diagram has recently been investigated by thermal conductivity measurements, which show that in the range 100 to $400 \mathrm{~K}$, and at pressures up to $2 \mathrm{GPa}$, there are no anomalies indicating any phase transformations in $\mathrm{KBH}_{4}$ [30]. (It should be noted that the cubic to tetragonal transformation in $\mathrm{NaBH}_{4}$ gives rise to large anomalies, involving a step change by 25 percent $[30,54]$.) Figure 6 shows a tentative phase diagram for $\mathrm{KBH}_{4}$, drawn from the information supplied above. The phase lines for both the $P 4_{2} / n m c$ low temperature tetragonal phase and the high-pressure $P \overline{4} 2_{1} c$ tetragonal phase have been drawn with the steepest possible slopes compatible with the thermal conductivity study of Sundqvist and Andersson [30]. Because phase lines 


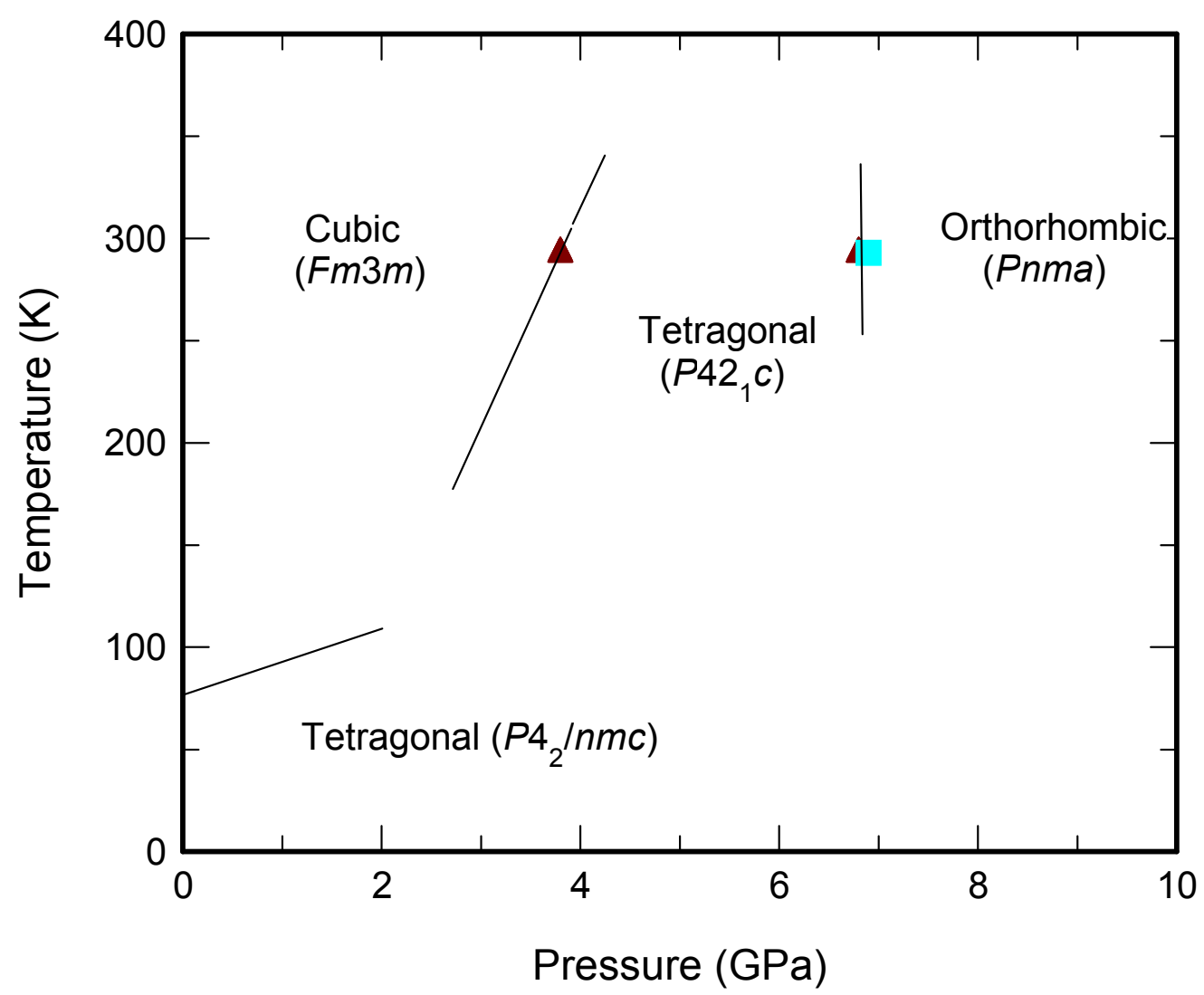

Fig. 6 Preliminary phase diagram of $\mathrm{KBH}_{4}$. Sundqvist and Andersson [30] find no transitions above $100 \mathrm{~K}$ at pressures up to $2 \mathrm{GPa}$, limiting possible slopes for transition from/to the cubic phase. Symbols denote transformation anomalies found in Refs. [44] (square) and [56] (triangles).

drawn as temperature versus pressure usually decrease their slope with increasing pressure, the two cubic-tetragonal phase lines drawn from the reported experiments most probably must meet at a triple point in the diagram. The report of a $P \overline{4} 2_{1} c$ high-pressure tetragonal phase at room temperature [56] therefore implies a rather complicated phase diagram with two different tetragonal phases existing below room temperature, and further investigations of this system under pressure are clearly required.

$\mathrm{RbBH}_{4}$ and $\mathrm{CsBH}_{4}$ both have the same $F m \overline{3} m$ cubic structure as the lighter borohydrides at room temperature, and both have been reported to transform into other phases at low temperatures, about $44 \mathrm{~K}$ for $\mathrm{RbBH}_{4}$ and $27 \mathrm{~K}$ for $\mathrm{CsBH}_{4}[48,57]$. However, the detailed structures have not been identified since the transformations are quite sluggish and do not seem to be completed even at liquid helium temperatures [48]. Resistance measurements under pressure have shown indications of a phase transformation above $3 \mathrm{GPa}[10]$ in $\mathrm{RbBH}_{4}$, but no other experimental studies have yet been reported. Theoretical calculations have also been carried out to find the structures at atmospheric pressure, but except for predictions that the bulk moduli should be 6.2 and $5.2 \mathrm{GPa}$, respectively, for the $\mathrm{Rb}$ and $\mathrm{Cs}$ compounds [43], no high-pressure properties have been given. Guided by the structural similarity with the $\mathrm{K}$ and $\mathrm{Rb}$ compounds we can make an "educated guess" that transformations into (probably orthorhombic) structures will occur under pressure at room temperature, probably at rather low pressures below $5 \mathrm{GPa}$ because of the low predicted bulk moduli.

Finally, we note that the synthesis of a mixed lithium-potassium borohydride, $\operatorname{LiK}\left(\mathrm{BH}_{4}\right)_{2}$, was recently reported [58]. This mixed compound was found to have an orthorhombic Pnma structure closely related to that of $\mathrm{LiBH}_{4}$. While the hydrogen weight fraction is similar to that of $\mathrm{NaBH}_{4}$, the 
new compound had a somewhat lower decomposition temperature. No high-pressure data are yet available for this material, not for any other mixed borohydrides.

\section{Other Complex Hydrides}

Other complex hydrides have also been suggested as hydrogen storage materials. From the mass fraction point of view, alkali metal beryllium hydrides should be quite efficient since $\mathrm{LiBeH}_{3}$ and $\mathrm{Li}_{2} \mathrm{BeH}_{4}$ contain 15.8 and 14.9 percent hydrogen, respectively. The structures of both materials have been determined, and they have been investigated by theoretical methods [59,60]. No information about the high pressure properties of $\mathrm{LiBeH}_{3}$ or of other similar alkali beryllium compounds is given [60], but $\mathrm{Li}_{2} \mathrm{BeH}_{4}$ has been theoretically predicted [59] to have a phase transition with a 5 percent change in volume near $18 \mathrm{GPa}$, from its zero-pressure monoclinic $P 2{ }_{1} / c$ structure [61] into an orthorhombic Pnma $\beta$ phase. No experimental data are available, although $\mathrm{Hu}$ et al. [59] refer to unpublished work by Lipinska-Kalita et al. Although these beryllium compounds are, in principle, interesting, their high toxicity probably makes them unsuitable for practical applications.

The alkaline earth borohydrides and alanates may also be used to store very high weight fractions of hydrogen. The beryllium compounds $\mathrm{Be}\left(\mathrm{BH}_{4}\right)_{2}$ [62] and $\mathrm{Be}\left(\mathrm{AlH}_{4}\right)_{2}$ contain 20.7 and 11.2 percent hydrogen by weight, respectively, but again the toxicity of $\mathrm{Be}$ is probably too high for practical applications. The magnesium compounds $\mathrm{Mg}\left(\mathrm{BH}_{4}\right)_{2}$ and $\mathrm{Mg}\left(\mathrm{AlH}_{4}\right)_{2}$ contain 14.8 and 9.3 percent hydrogen, still showing a very good potential for hydrogen storage, and during the last few years a very large amount of work has been concentrated on these materials. However, although hydrogen can easily be released thermally the process has not been shown to be reversible.

So far, little work has been carried out on the properties and structures of any of these materials under high pressure. The only available data are provided by $\mathrm{Hu}$ et al. [63], who recently carried out DFT calculations for $\mathrm{Mg}\left(\mathrm{AlH}_{4}\right)_{2}$. Their results showed that the trigonal $P \overline{3} m 1 \alpha$ structure observed at atmospheric pressure should be only marginally stable and should transform already at a very low pressure, $0.68 \mathrm{GPa}$, into a $\beta$ phase with a monoclinic $C 2 / m$ structure. This structure was found to be stable up to $10.3 \mathrm{GPa}$, above which a $\gamma$ phase with an orthorhombic Pbca structure should exist. Both phase transitions were predicted to involve rather large volume changes of 6.6 and 8.7 percent, respectively, and the calculated bulk moduli for the $\alpha, \beta$, and $\gamma$ phases were found to be $\mathrm{B}_{0}=9.2$, 6.8, and 34.7 GPa.

In contrast to $\mathrm{Mg}\left(\mathrm{AlH}_{4}\right)_{2}$, hydrogen release from $\mathrm{Mg}\left(\mathrm{BH}_{4}\right)_{2}$ seems to be at least partially reversible [64], and the higher hydrogen content thus makes this material a very interesting candidate for storage applications. The two known phases of $\operatorname{Mg}\left(\mathrm{BH}_{4}\right)_{2}$ have very complicated structures which were identified only very recently $[65,66]$. The low-temperature phase structure is hexagonal with symmetry $P 6_{1}$ and 30 formula units in the unit cell $[65,66]$, while the high temperature phase is orthorhombic Fddd with 64 formula units per cell [66]. The transition temperature is not well defined and these phases seem to coexist over a wide range of temperatures. Many simpler structures have been suggested based on both calculations and experiments, and it is possible that future high-pressure studies will discover that some of these may also exist. In particular, Ozolins et al. [67] recently predicted that a tetragonal $I \overline{4} m 2$ structure should have a significantly lower energy than either of the structures observed in experiments. However, the low density of the predicted phase makes it unlikely that it would exist under pressure.

The calcium complex hydrides have also been investigated, in particular $\mathrm{Ca}\left(\mathrm{BH}_{4}\right)_{2}$ which contains 11.5 percent hydrogen and shows at least partial reversibility in its hydrogen storage properties [68]. As in $\mathrm{Mg}\left(\mathrm{BH}_{4}\right)_{2}$, at least two phases are observed to coexist over wide ranges of temperature. At room temperature, an orthorhombic Fddd $\alpha$ phase dominates [69], while heating to above $400 \mathrm{~K}$ produces a tetragonal $P 4_{2} / m \beta$ phase [70]. A third $\gamma$ phase, tentatively indexed as orthorhombic Pbca, has also been reported [70], but nothing is yet known about the high-pressure evolution of these structures. $\mathrm{Ca}\left(\mathrm{AlH}_{4}\right)_{2}$, containing 7.8 percent hydrogen, has also been discussed as a possible hydrogen source. Its structure still seems to be unidentified, although it has been 
theoretically predicted to be orthorhombic $\mathrm{Pbca}[71,72]$, and again nothing is known about its highpressure properties.

Finally, it has been argued that for the heavier alkaline earth hydrides, $\mathrm{M}^{\prime} \mathrm{AlH}_{5}$ (with $\mathrm{M}^{\prime}$ an alkaline earth metal) may be (irreversibly) formed from $\mathrm{M}^{\prime}\left(\mathrm{AlH}_{4}\right)_{2}$ as an intermediate phase in the dehydration process [71]. The $\mathrm{M}^{\prime} \mathrm{AlH}_{5}$ family of materials are thus potentially related to the $\mathrm{M}^{\prime}\left(\mathrm{AlH}_{4}\right)_{2}$ materials in the same way as the $\mathrm{M}_{3} \mathrm{AlH}_{6}$ materials are to the $\mathrm{MAlH}_{4}$ family. The structures of the $\mathrm{M}^{\prime} \mathrm{AlH}_{5}$ compounds are thus also of some scientific and technical interest for hydrogen storage and have recently been predicted theoretically [72-75] and, in two cases, verified by experiments $[75,76]$. Klaveness et al. have systematically predicted the structures of all these compounds. For $\mathrm{BeAlH}_{5}$ (with 12.2 percent hydrogen) they predict a monoclinic $P 2_{1}$ structure at atmospheric pressure, with a low-pressure structural phase transformation at $1.3 \mathrm{GPa}$ into a more dense $C 2 / c$ structure [74]. $\mathrm{MgAlH}_{5}$ is predicted by Klaveness et al. [73] to have a monoclinic $P 2_{1} / c$ $\alpha$ structure, but there is a monoclinic $C c \beta$ phase with a very similar energy and a slightly expanded lattice, which may also be stable, perhaps at higher temperatures. However, Wolverton and Ozolinšs [72] disagree that the $P 2_{1} / c$ structure has the lowest energy, without presenting an alternative. For $\mathrm{CaAlH}_{5}$, Weidenthaler et al. [75] have identified a monoclinic $P 2_{1} / n$ structure by X-ray diffraction studies, and this structure is also predicted by calculations [72, 74, 75]. Klaveness et al. [74] predict that a high-pressure transformation will occur into a $P 2{ }_{1} 2{ }_{1} 2_{1} \beta$ phase near $4.5 \mathrm{GPa}$. Surprisingly, the high-pressure phases of both $\mathrm{BeAlH}_{5}$ and $\mathrm{CaAlH}_{5}$ are predicted to have lower values for their bulk moduli $\mathrm{B}_{0}$ than the ambient pressure phases [74]. The structure of $\mathrm{BaAlH}_{5}$ has been identified as orthorhombic $P n a 2_{1}$ by neutron diffraction [76], in agreement with later calculations [73], and $\mathrm{SrAlH}_{5}$ is predicted to be isostructural with the $\mathrm{CaAlH}_{5} P 2{ }_{1}{ }_{2} 2_{1} \beta$ phase [74]. The $\mathrm{M}^{\prime} \mathrm{AlH} \mathrm{H}_{5}$ all have interesting structures, most based on non-linear chains of linked $\mathrm{AlH}_{6}$ octahedra with the alkaline earth ions as spacers.

\section{Final Comments and Conclusions}

The structural diversity among the complex hydrides is quite surprising even at atmospheric pressure, considering that most structures are based on very simple building blocks, i.e. metal ions and small hydride complexes such as $\mathrm{BH}_{4}$. Under high pressure, an even greater variety of structures can be expected to appear, and high-pressure studies of complex hydrides are clearly at present a very interesting and rapidly evolving field. However, the mapping of equilibrium structures and phases is in many cases an almost impossible task, given that many materials, especially among the alanates, show extremely strong effects of hysteresis and metastability. For example, the $\beta$ phase of $\mathrm{NaAlH}_{4}$ has a range of pressure metastability of about $10 \mathrm{GPa}$, equivalent to 100000 times atmospheric pressure. While this may be very bad news for investigations of the basic properties of the materials it may turn out to be very important for applications, since it indicates strong possibilities that dense, metastable phases might be stabilized near atmospheric pressure.

An interesting question is, of course, whether we can identify any structural trends that might simplify the search for such possible dense structures and/or help us predict the structural phase diagrams of new or existing materials under pressure. The $\mathrm{MBH}_{4}$ compounds, with the exception of $\mathrm{LiBH}_{4}$, have very similar structures at atmospheric pressure, and so far the high pressure evolution seems to be to rather similar with the phase boundaries basically shifting to lower pressures and lower temperatures with increasing alkali metal mass. In fact, once $\mathrm{LiBH}_{4}$ has been densified by the application of pressure it also seems to prefer structures in the cubic family like its heavier relatives. For other families of materials systematic trends are more difficult to find. For the $\mathrm{MAlH}_{4}$ and $\mathrm{M}_{3} \mathrm{AlH}_{6}$ materials there is a (predicted) tendency to end up in orthorhombic high-pressure structures, but there is a bewildering number of observed or predicted structural sequences with increasing pressure, and much work remains before any systematic trends can be ascertained. The $\mathrm{M}^{\prime} \mathrm{AlH}_{5}$ family also shows a simple evolution of the (predicted) ambient structures with alkaline earth mass, but only two structures have yet been experimentally identified. 
With the rapidly increasing interest in alternative energy sources and energy carriers the field of hydrogen storage quickly becomes more important. The use of complex hydrides as storage media is in principle among the most efficient ways to store large amounts of hydrogen in a reasonable volume and with a reasonable weight (even including containers), and in several cases hydrogen can be released, perhaps even reversible, using simple methods. Research in this area is thus expected to continue to evolve rapidly, and the interest in the structural properties of these materials at both atmospheric and high pressure will probably continue to increase in the future.

\section{References}

[1] L. Schlapbach and A. Züttel: Nature Vol. 414 (2001), p. 353

[2] B. Bogdanović and M.J. Schwickardi: J. Alloy Compd. Vols. 253-254 (1997), p. 1

[3] P. Vajeeston, P. Ravindran, R. Vidya, H. Fjellvåg and A. Kjekshus: Phys. Rev. B Vol. 68 (2003), art. no. 212101

[4] J. Chen, N. Kuriyama, Q. Xu, H.T. Takeshita and T. Sakai: J. Phys. Chem. B Vol. 105 (2001), p. 11214

[5] J. Wang, A.D. Ebner and J.A. Ritter: J. Am. Chem. Soc. Vol. 128 (2006), p. 5949

[6] B. Bogdanović and G. Sandrock: MRS Bull. Vol. 27 (2002), p. 712

[7] J.-W. Jang, J.-H. Shim, Y.W. Cho and B.-J. Lee: J. Alloy Compd. Vol. 420 (2006), p. 286

[8] X.Z. Ke and C.F. Chen: Phys. Rev. B Vol. 76 (2007), art. no. 024112

[9] D.T. Griggs, W.G. McMillan, E.D. Michael and P. Nash: Phys. Rev. Vol. 109 (1958), p. 1858

[10]K. Wakamori, A. Sawaoka, S.M. Filipek and B. Baranowski: J. Less-Common Metals Vol. 88 (1982), p. 217

[11]B.J. Alder and R.H. Christian: Phys. Rev. Vol. 104 (1956), p. 550

[12]B.M. Bulychev, V.N. Verbetskii and K.N. Semenenko: Russ. J. Inorg. Chem. Vol. 22 (1977), p. 611

[13]J.-P. Bastide, J.-C. Bureau, J.-M. Létoffé and P. Claudy: Mater. Res. Bull. Vol. 22 (1988), p. 185

[14] S.K. Konovalov, B.M. Bulychev and V.K. Genchel': Russ. J. Inorg. Chem. Vol. 35 (1990), p. 327

[15]P. Ravindran, P. Vajeeston, R. Vidya, H. Fjellvåg and A. Kjekshus: J. Power Sources Vol. 159 (2006), p. 88

[16]A.V. Talyzin and B. Sundqvist: Phys. Rev. B Vol. 70 (2004), art. no. 180101

[17] A.V. Talyzin, B. Sundqvist, C.M. Araújo and R. Ahuja, in: Proceedings on Joint $20^{\text {th }}$ AIRAPT and on $43^{\text {rd }}$ EHPRG Confenference on High Pressure Science and Technology, Karlsruhe 2005, edited by E. Dinjus and N. Dahmen, Forschungszentrum Karlsruhe (2005), paper available free at http://www.unipress.waw.pl/airapt/AIRAPT-20/html/proceedings/index.html

[18] R.S. Chellappa, D. Chandra, S.A. Gramsch, R.J. Hemley, J.F. Lin and Y. Song: J. Phys. Chem. B Vol. 110 (2006), p. 11088

[19] R. Chellappa, D. Chandra, S. Gramsch, M. Somayazulu and R. Hemley: Mater. Res. Soc. Symp. Proc. Vol. 987 (2007), art. no. 0987-PP04-10

[20] M.P. Pitt, D. Blanchard, B.C. Hauback, H. Fjellvåg and W.G. Marshall: Phys. Rev. B Vol. 72 (2005), art. no. 214113 
[21]H.W. Brinks and B.C. Hauback: J. Alloys Compd. Vol. 354 (2003), p. 143

[22] R.S. Kumar, X.Z. Ke, A.L. Cornelius and C.F. Chen: Chem. Phys. Lett. Vol. 460 (2008), p. 442

[23] J.P. Bastide,B.M. Bonnetot, J.M. Létoffé and P. Claudy, in: Solid State Chemistry 1982, edited by R. Metselaar, H.J.M. Heijligers and J. Schoonman, volume 3 of Studies in Inorganic Chemistry, Elsevier Scientific Publishing Company, Amsterdam (1983).

[24]P. Vajeeston, P. Ravindran, A. Kjekshus and H. Fjellvåg: Phys. Rev. B Vol. 69 (2004), art. no. 020104

[25]P. Vajeeston, P. Ravindran, R. Vidya, H. Fjellvåg and A. Kjekshus: Appl. Phys. Lett. Vol. 82 (2003), p. 2257

[26] S. Nakano, A. Nakayama and K. Takemura, in: Proceedings on Joint $20^{\text {th }}$ AIRAPT and on $43^{\text {rd }}$ EHPRG Confenference on High Pressure Science and Technology, Karlsruhe 2005, edited by E. Dinjus and N. Dahmen, Forschungszentrum Karlsruhe (2005), available free at http://www.unipress.waw.pl/airapt/AIRAPT-20/html/proceedings/index.html

[27]A.V. Talyzin and B. Sundqvist: High Pressure Res. Vol. 26 (2006), p. 165

[28]R.S. Kumar, E. Kim, O. Tschauner, A.L. Cornelius, M.P. Sulic and C.M. Jensen: Phys. Rev. B Vol. 75 (2007), art. no. 174110

[29] B. Sundqvist, O. Andersson and V.A. Talyzin: J. Phys.: Cond. Matter Vol. 19 (2007), art. no. 425201.

[30]B. Sundqvist and O. Andersson: To be published.

[31] J.-P. Bastide, B. Bonnetot, J.-M. Létoffé and P. Claudy: Mater. Res. Bull. Vol. 16 (1981), p. 91

[32]P. Vajeeston, P. Ravindran, A. Kjekshus and H. Fjellvåg: Phys. Rev. B Vol. 71 (2005), art. no. 092103

[33]H. Morioka, K. Kakizaki, S.C. Chung and A. Yamada: J. Alloy Compd. Vol. 353 (2003), p. 310

[34] J.-P. Bastide, P. Claudy, J.-M. Létoffé and J. el Hajri: Rev. Chim. Minérale Vol. 24 (1987), p. 248

[35] P. Ravindran, P. Vajeeston, H. Fjellvåg and A.. Kjekshus: Comp. Mater. Sci. Vol. 30 (2004), p. 349.

[36] J. Graetz, Y. Lee, J.J. Reilly, S. Park and T. Vogt: Phys. Rev. B Vol. 71 (2005), art. no. 184115

[37]P. Mauron, F. Buchter, O. Friedrichs, A. Remhof, M. Bielmann, C.N. Zwicky and A. Züttel: J. Phys. Chem. B Vol. 112 (2008), p. 906.

[38] J.-P. Soulié, G. Renaudin, R. Cerny and K. Yvon: J. Alloys Compd. Vol. 346 (2002), p. 200

[39] Y. Filinchuk, D. Chernyshov and R. Cerny: J. Phys. Chem. C Vol. 112 (2008), p. 10579

[40]Z. Łodziana and T. Vegge: Phys. Rev. Lett. Vol. 93 (2004), art. no. 145501

[41] T.J. Frankcombe, G.-J. Kroes and A. Züttel: Chem. Phys. Lett: Vol. 405 (2005), p. 73

[42] C.W.F.T. Pistorius: Z. Phys. Chem. Neue Folge Vol. 88 (1974), p. 253

[43] P. Vajeeston, P. Ravindran, A. Kjekshus and H. Fjellvåg: J. Alloy Compd. Vol. 387 (2005), p. 97

[44] B. Sundqvist, A.V. Talyzin and O. Andersson: Mater. Res. Soc. Symp. Proc. Vol. 971E (2007), art. no. 0971-Z07-03 
[45] A.V. Talyzin, O. Andersson, B. Sundqvist, A. Kurnosov and L. Dubrovinsky: J. Solid State Chem. Vol. 180 (2007), p. 510

[46] Y. Filinchuk, D. Chernyshov, A. Nevidomskyy and V. Dmitriev: Angew. Chem. Int. Ed. Vol. 47 (2008), p. 529

[47] V. Dmitriev, Y. Filinchuk, D. Chernyshov, A.V. Talyzin, A. Dzwilevski, O. Andersson, B. Sundqvist and A. Kurnosov: Phys. Rev. B Vol. 77 (2008), art. no. 174112

[48] G. Renaudin, S. Gomes, H. Hagemann, L. Keller and K. Yvon: J. Alloys Compd. Vol. 375 (2004), p. 98

[49]D. Sihachakr, R. André and P. Loubeyre, in: Proceedings on Joint $20^{\text {th }}$ AIRAPT and on $43^{\text {rd }}$ EHPRG Confenference on High Pressure Science and Technology, Karlsruhe 2005, edited by E. Dinjus and N. Dahmen, Forschungszentrum Karlsruhe (2005), available free at http://www.unipress.waw.pl/airapt/AIRAPT-20/html/proceedings/index.html

[50] C.M. Araújo, R. Ahuja, A.V. Talyzin and B. Sundqvist: Phys. Rev. B Vol. 72 (2005), art. no. 054125

[51] R.S. Kumar and A.L. Cornelius: Appl. Phys. Lett. Vol.n87 (2005), art. no. 261916

[52] Y. Filinchuk, A.V. Talyzin, D. Chernyshov and V. Dmitriev: Phys. Rev. B Vol. 76 (2007), art. no. 092104

[53] E. Kim, R. Kumar, P.F. Weck, A.L. Cornelius, M. Nicol, S.C. Vogel, J.Z. Zhang, M. Hartl, A.C. Stowe, L. Daemen and Y.S. Zhao: J. Phys. Chem. B Vol. 111 (2007), p. 13873

[54]B. Sundqvist and O. Andersson: Phys. Rev. B Vol. 73 (2006), art. no. 092102

[55] G. Lee, J.-Y. Lee and J.S. Kim: Solid State Commun. Vol. 139 (2006), p. 516

[56] R.S. Kumar, E. Kim and A.L. Cornelius: J. Phys. Chem. C Vol. 112 (2008), p. 8452

[57] C.C. Stephenson, D.W. Rice and W.H. Stockmeyer: J. Chem. Phys. Vol. 23 (1955), p. 1960

[58]E.A. Nickels, M.O. Jones, W.I.F. David, S.R. Johnson, R.L. Lowton, M. Sommariva and P.P. Edwards: Angew. Chem. Int. Ed. Vol. 47 (2008), p. 2817

[59] C.H. Hu, D.M. Chen, Y.M. Wang, D.S. Xu and K. Yang: Phys. Rev. B Vol. 75 (2007), art. no. 224108.

[60]P. Vajeeston, P. Ravindran and H. Fjellvåg: Inorg. Chem. Vol. 47 (2008), p. 508

[61] B.M. Bulychev, R.V. Shpanchenko, E.V. Antipov, D.V. Sheptyakov, S.N. Bushmeleva and A.M. Balagurov: Inorg. Chem. Vol. 43 (2004), p. 6371.

[62] M.J. van Setten, G.A. de Wijs and G. Brooks: Phys. Rev. B Vol. 77 (2008), art. no. 165115

[63] C.H. Hu, D.M. Chen, Y.M. Wang, D.S. Xu and K. Yang: J. Phys.: Condens. Matter Vol. 19 (2007), art. no. 176205

[64]H.-W. Li, K. Kikuchi, Y. Nakamori, N. Ohba, K. Miwa, S. Towata and S. Orimo: Acta Mater. Vol. 56 (2008), p. 1342

[65] R. Černý, Y. Filinchuk, H. Hagemann and K. Yvon: Angew. Chem. Int. Ed. Vol. 46 (2007), p. 5765

[66] J.-H. Her, P.W. Stephens, Y. Gao, G.L. Soloveichik, J. Rijssenbeek, M. Andrus and J.-C. Zhao: Acta Cryst. B Vol. 63 (2007), p. 561

[67] V. Ozolins, E.H. Majzoub and C. Wolverton: Phys. Rev. Lett. Vol. 100 (2008), art. no. 135501

[68]E. Rönnebro and E.H. Majzoub: J. Phys. Chem. B Vol. 111 (2007), p. 12045 
[69] K. Miwa, M. Aoki, T. Noritake, N. Ohba, Y. Nakamori, S.-I. Towata, A. Züttel and S.-I. Orimo: Phys. Rev. B Vol. 74 (2006), art. no. 155122

[70]F. Buchter, Z. Łodziana, A. Remhof, O. Friedrichs, A. Borgschulte, Ph. Mauron, A. Züttel, D. Sheptyakov, G. Barkhordarian, R. Bormann, K. Chłopek, M. Fichtner, M. Sørby, M. Riktor, B. Hauback and S. Orimo: J. Phys. Chem. B Vol. 112 (2008), p. 8042

[71] O.M. Løvvik: Phys. Rev. B Vol. 71 (2005), art. no. 144111

[72] C. Wolverton and V. Ozolinšs: Phys. Rev. B Vol. 75 (2007), art. no. 064101

[73] A. Klaveness, P. Vajeeston, P. Ravindran, H. Fjellvåg and A. Kjekshus: Phys. Rev. B Vol. 73 (2006), art. no. 094122.

[74]A. Klaveness, P. Vajeeston, P. Ravindran, H. Fjellvåg and A. Kjekshus: J. Alloy Compd. Vol. 433 (2007), p. 225

[75] C. Weidenthaler, T.J. Frankcombe and M. Felderhoff: Inorg. Chem. Vol. 45 (2006), p. 3849

[76]Q.-A. Zhang, Y. Nakamura, K.-I. Oikawa, T. Kamiyama and E. Akiba: Inorg. Chem. Vol. 41 (2002), p. 6941 